\title{
Characterization of methane retrievals from the IASI space-borne sounder
}

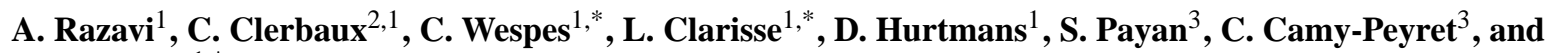 \\ P. F. Coheur ${ }^{1, *}$ \\ ${ }^{1}$ Service de Chimie Quantique et Photophysique, Université Libre de Bruxelles (U.L.B.), Brussels, Belgium \\ ${ }^{2}$ UPMC Univ. Paris 06; Université Versailles St-Quentin; CNRS/INSU, LATMOS-IPSL, Paris, France \\ ${ }^{3}$ UPMC Univ Paris 06, CNRS UMR7092, LPMAA/IPSL, Paris, France \\ *They are, respectively FRIA researcher, Scientific collaborator and Research Associate with FRS-FNRS, Belgium
}

Received: 6 February 2009 - Published in Atmos. Chem. Phys. Discuss.: 23 March 2009

Revised: 29 September 2009 - Accepted: 1 October 2009 - Published: 21 October 2009

\begin{abstract}
Although the global methane $\left(\mathrm{CH}_{4}\right)$ concentration has more than doubled since pre-industrial times, local emission sources are still poorly identified and quantified. Instruments onboard satellites can improve our knowledge about the methane global distribution owing to their very good spatial coverage. The IASI (Infrared Atmospheric Sounding Interferometer) instrument launched on the European MetOp-A platform is a Fourier transform spectrometer which measures the thermal infrared radiation emitted by the Earth and its atmosphere. In this paper, we present the first global distribution of methane total columns (mostly sensitive to the middle troposphere) from the IASI spectra using the methane $v_{4}$ absorption band. The retrieval spectral range was set in order to minimize possible spectroscopic issues. Results are discussed in terms of error budget and vertical sensitivity. In addition, we study the gain of information on surface methane concentrations provided by using the $v_{3}$ band, which is partly covered by IASI on the short-wave end of the spectra (extending to $2760 \mathrm{~cm}^{-1}$ ), where solar reflection contributes significantly.
\end{abstract}

\section{Introduction}

Despite the fact that methane $\left(\mathrm{CH}_{4}\right)$ is the second most important anthropogenic greenhouse gas in our atmosphere, large uncertainties still exist on the location and intensity of

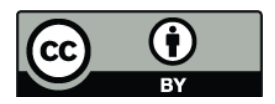

Correspondence to: A. Razavi

(arazavi@ulb.ac.be) the emission sources. These emissions are mostly related to anaerobic decomposition and can be classified into natural sources (wetlands, oceans, forests, fires, termites and geological sources) and anthropogenic sources (rice agriculture, livestock, landfills, waste treatment, biomass burning, and fossil fuel combustion). About $60 \%$ of the $\mathrm{CH}_{4}$ released in the atmosphere is related to human activities (Denman et al., 2007).As a result, its concentration has more than doubled since pre-industrial times, reaching $1774 \pm 1 \mathrm{ppb}$ in 2005 (Forster et al., 2007). From the 1980's, the increase in methane has been slowing down, reaching a steady state around the year 2000 (but see Rigby et al., 2008). This phenomenon is not yet fully understood but a stabilization of $\mathrm{CH}_{4}$ emissions has been suggested (Dlugokencky et al., 2003). Methane also plays a key role in the chemical processes occurring in the troposphere through its oxidation by the $\mathrm{OH}$ radical. This reaction is the main $\mathrm{CH}_{4}$ sink, contributing to more than $80 \%$ of its total loss in the troposphere (Denman et al., 2007). Other minor removal processes include uptake by soil and transport to the stratosphere where $\mathrm{CH}_{4}$ is rapidly destroyed.

Observations from space which offer a very good spatiotemporal coverage, are useful to improve our knowledge of the relative strengths of the methane sources and sinks. In recent years, different instruments on board satellites have enabled mapping the methane concentrations in our atmosphere. The SCIAMACHY instrument onboard ENVISAT, operating in the UV, visible and near infrared spectral regions has delivered annual global distributions of $\mathrm{CH}_{4}$ (Frankenberg et al., 2006). These have been recently revised after using a new set of spectroscopic parameters (Frankenberg

Published by Copernicus Publications on behalf of the European Geosciences Union. 

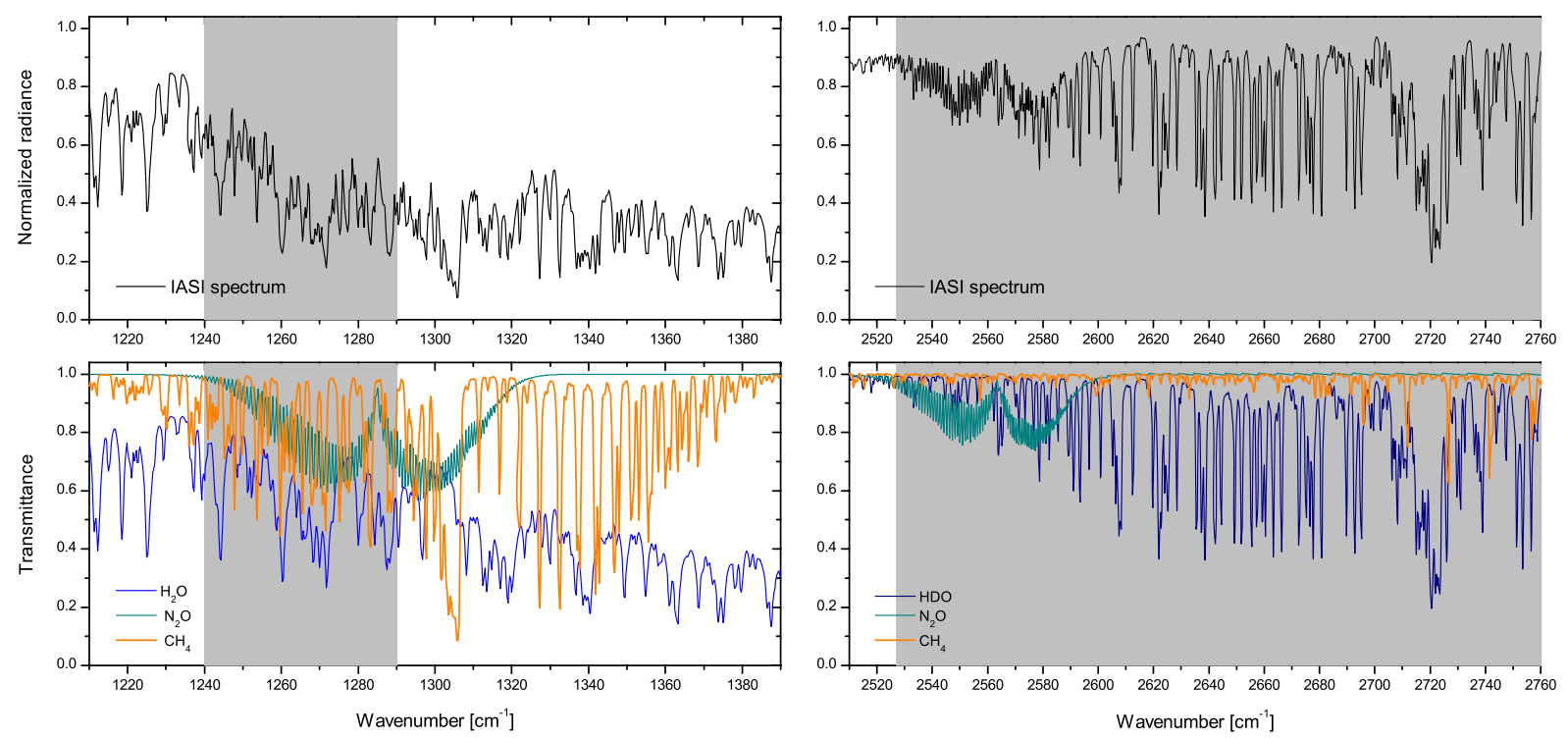

Fig. 1. IASI normalised radiance spectrum in the two spectral regions containing methane absorption (top), along with the main interfering species (bottom), plotted in transmittance. The grey areas indicate the spectral regions used to retrieve methane. Left panel: The methane $v_{4}$ band extending from 1210 to $1390 \mathrm{~cm}^{-1}$. Right panel: Methane absorption lines (P branch) within the $v_{3}$ band centered at $3020 \mathrm{~cm}^{-1}$, observed at the far end of the IASI spectral range.

et al., 2008a), leading to improved retrievals of water vapor and methane, with a net decrease of tropical $\mathrm{CH}_{4}$ concentrations (Frankenberg et al., 2008b). The SCIAMACHY methane distributions present high concentrations in the tropical region, which are possibly related to methane emission from terrestrial plants (Keppler et al., 2006). This question is still subject to some controversy (Dueck et al., 2007) but has recently been confirmed in two studies (Keppler et al., 2008; Vigano et al., 2008). $\mathrm{CH}_{4}$ profiles can also be retrieved from thermal infrared nadir sounders, as was shown from the IMG/ADEOS mission (Clerbaux et al., 2003) and more recently from the AIRS/AQUA and TES/Aura sounders (Xiong et al., 2008; Kulawik et al., 2008). Space-borne instruments working in a limb viewing geometry (ACE-FTS, HALOE, MIPAS) add information on the vertical distribution of methane but are only sensitive from the upper troposphere to higher altitudes (De Mazière et al., 2008; Raspollini et al., 2006; Park et al., 2004).

The IASI (Infrared Atmospheric Sounding Interferometer) (Phulpin et al., 2007) thermal infrared sounder is an instrument taking measurements of atmospheric composition and meteorology with an excellent spatial resolution and coverage, which enables the delivery of global distributions twice a day (Clerbaux et al., 2007). Primarily designed for meteorological purposes, IASI provides also information on different trace gases important for climate monitoring $\left(\mathrm{CO}_{2}\right.$, $\mathrm{H}_{2} \mathrm{O}$ (Herbin et al., 2009), $\mathrm{CH}_{4}$ ) and atmospheric chemistry, such as CO (George et al., 2009; Turquety et al., 2009), $\mathrm{O}_{3}$ (Boynard et al., 2009), $\mathrm{HNO}_{3}$ (Wespes et al., 2009) and $\mathrm{NH}_{3}$ (Clarisse et al., 2009). It also allows the detection of mi- nor trace gases during exceptional events such as fires (Coheur et al., 2009) or volcanic eruptions (Clarisse et al., 2008). IASI covers an extended spectral range which allows the retrieval of methane using two different spectral regions corresponding to the $v_{4}$ and $v_{3}$ rovibrational bands (Fig. 1). In this work, we focus on the characterization of $\mathrm{CH}_{4}$ retrievals from the $v_{4}$ band and investigate the possibility of retrieving additional information on surface concentrations using the $v_{3}$ band.

In the next section, we briefly describe the IASI measurements and the method used to retrieve methane. The importance of methane line mixing is discussed as well. Global distributions of methane retrieved from the $v_{4}$ band are presented and discussed in Sect. 3 along with detailed characterizations of retrieved profiles in both bands. Finally, in Sect. 4 we draw conclusions and provide perspectives on future work.

\section{IASI instrument and concentration measurement}

\subsection{Description of IASI}

The IASI instrument, consisting of a nadir-looking Fourier transform spectrometer, was launched onboard the MetOpA platform on 19 October 2006 and flies at about $817 \mathrm{~km}$ on a polar sun-synchronous orbit. It records the Earth's outgoing radiation from 645 to $2760 \mathrm{~cm}^{-1}$ with an apodized resolution of $0.5 \mathrm{~cm}^{-1}$. Because of the wide scans across its track (2200 km swaths), IASI provides global Earth's coverage twice a day with a field of view defined at nadir by a 
matrix of 4 circular pixels of $12 \mathrm{~km}$ diameter each. Moreover, IASI offers a very good signal-to-noise ratio. The on-flight Noise Equivalent Delta Temperature (NEDT) at $280 \mathrm{~K}$ has been estimated to be well below $0.1 \mathrm{~K}$ in the spectral range of interest for methane. The IASI mission delivers data operationally since late May 2007 and is planned to last 15 years with the successive launch of two other identical instruments, providing consistent measurements on a large time scale.

The IASI spectral range covers entirely the $v_{4}$ rovibrational band, corresponding to the bending mode of methane around $1306 \mathrm{~cm}^{-1}$ as well as some lines of the $\nu_{3}$ band (stretching mode) near $2700 \mathrm{~cm}^{-1}$. The region above $2200 \mathrm{~cm}^{-1}$ is significantly affected by solar radiation reflected on the Earth's surface. The use of the $v_{3}$ band eliminates the negative effect of weak thermal contrast on the IR sounding in the boundary layer and is accordingly expected to improve the retrievals of $\mathrm{CH}_{4}$ concentration near the Earth's surface. These two absorption regions are illustrated in Fig. 1 together with the overlapping contributions of other molecules (mainly $\mathrm{N}_{2} \mathrm{O}, \mathrm{H}_{2} \mathrm{O}$ and $\mathrm{HDO}$ ). The gray areas represent the spectral windows selected for the retrievals. These choices will be explained in Sects. 2.3 and 3.3 for the $v_{4}$ and $v_{3}$ bands, respectively.

\subsection{Retrieval method}

In this section we describe the method used to retrieve methane concentrations. The inversion model is based on the Optimal Estimation Method (OEM) (Rodgers, 2000) implemented in the Atmosphit software developed at the "Université Libre de Bruxelles". The latter also includes a sophisticated forward line-by-line radiation transfer model. For more details about the software, we refer the reader to Clarisse et al. (2008) and Coheur et al. (2005).

\subsubsection{Forward model}

The forward calculation of the radiance at a wavenumber evaluated at the top of the atmosphere $L_{\tilde{v}}^{\uparrow}(a)$ is made by solving the radiative transfer equation which includes one term accounting for the emission source $L_{\tilde{v}}^{\uparrow}(0)$ attenuated when passing through the atmosphere and another for the contribution of radiation emitted by the medium along the upward path $s^{\uparrow}$,

$L_{\tilde{\nu}}^{\uparrow}(a)=L_{\tilde{\nu}}^{\uparrow}(0) \tau_{\tilde{\nu}}^{\uparrow}\left(s^{\uparrow}\right)+\int_{s^{\uparrow}} B_{\tilde{\nu}}(T(s)) \frac{\partial \tau_{\tilde{\nu}}^{\uparrow}(s)}{\partial s} d s$

where $B_{\tilde{v}}(T(s))$ is the Planck function for a blackbody at temperature $T(s)$ and $\tau_{\tilde{v}}^{\uparrow}\left(s^{\uparrow}\right)$ is the transmittance along the path $s^{\uparrow}$ which is given by

$\tau_{\tilde{v}}^{\uparrow}\left(s^{\uparrow}\right)=$

$\exp \left(-\int_{s^{\uparrow}} \sum_{i} \Phi_{\tilde{\nu}, i}\left[p\left(s^{\prime}\right), T\left(s^{\prime}\right), n_{i}\left(s^{\prime}\right)\right] n_{i}\left(s^{\prime}\right) d s^{\prime}\right)$

www.atmos-chem-phys.net/9/7889/2009/
The sum in Eq. 2 applies over each molecular species $i$ and the coefficients $p$ and $n_{i}$ represent the atmospheric pressure and the number density, respectively. The quantity $\Phi_{\tilde{v}, i}$ corresponds to a discrete absorption line or to a continuous band (cross section or continuum) of a given species $i$.

For nadir looking satellites in the IR, the source is the Earth's thermal emission. The contribution of the averaged downward flux $L_{\tilde{v}}^{\downarrow}$ from the atmosphere, which is not absorbed by the Earth's surface needs also to be taken into account. Furthermore, for wavenumbers higher than about $2200 \mathrm{~cm}^{-1}$, an additional term must be introduced in the definition of the radiation source in order to account for the solar radiation reflected on the Earth's surface. As a result, the source term is given by

$$
\begin{aligned}
L_{\tilde{\nu}}^{\uparrow}(0) & =\epsilon B_{\tilde{\nu}}\left(T_{\text {skin }}\right) \\
& +\frac{(1-\epsilon)}{\pi} \int_{0}^{2 \pi} \int_{0}^{\pi / 2} L_{\tilde{\nu}}^{\downarrow}(\theta) \sin (\theta) \cos (\varphi) d \theta d \varphi \\
& +\eta B_{\tilde{v}}\left(T_{\text {Sun }}\right) \tau_{\tilde{\nu}}^{\downarrow}\left(s^{\downarrow}\right) .
\end{aligned}
$$

In the first term, $\epsilon$ is the emissivity of the Earth and $T_{\text {skin }}$ is the temperature derived from the thermal emission of the Earth's surface. The second term represents the contribution of the downward flux $L_{\tilde{v}}^{\downarrow}$ averaged over a half sphere. In the third term, $B_{\tilde{v}}\left(T_{\text {Sun }}\right)$ corresponds to the blackbody radiation emitted by the Sun and $\eta$, the reflectance, is the fraction of solar radiation reflected by the ground. The fraction of solar radiation present in a spectrum depends on numerous factors such as the local time of the measurement, the type of surface and the angle between the sun and the satellite; but it is considered independent from frequency for the small spectral interval used here. Figure 2 illustrates the importance of reflected solar radiation in the shortwave end of IASI spectra by comparing, in brightness temperature, one spectrum measured at night and another measured during daytime with significant solar reflection.

\subsubsection{Inverse model}

Equation (1) can be written as

$y=F(x ; b)+\rho$,

where $\boldsymbol{F}$ represents the radiative transfer function, $\boldsymbol{y}$ is the measurement vector which contains the recorded radiances, $\boldsymbol{x}$ represents the state vector (i.e. the atmospheric parameters we want to retrieve, which is the methane profile in our case), $\boldsymbol{b}$ are the other parameters which have an influence on the measurement (temperature and pressure profiles, instrumental properties, etc.) and $\rho$ is the measurement noise.

The inverse problem derived from Eq. (4) is generally illposed. An approximation $\hat{x}$ of the true state $\boldsymbol{x}$ can be found using the OEM described in Rodgers (2000). This statistical approach is based on the combination of the measurement 


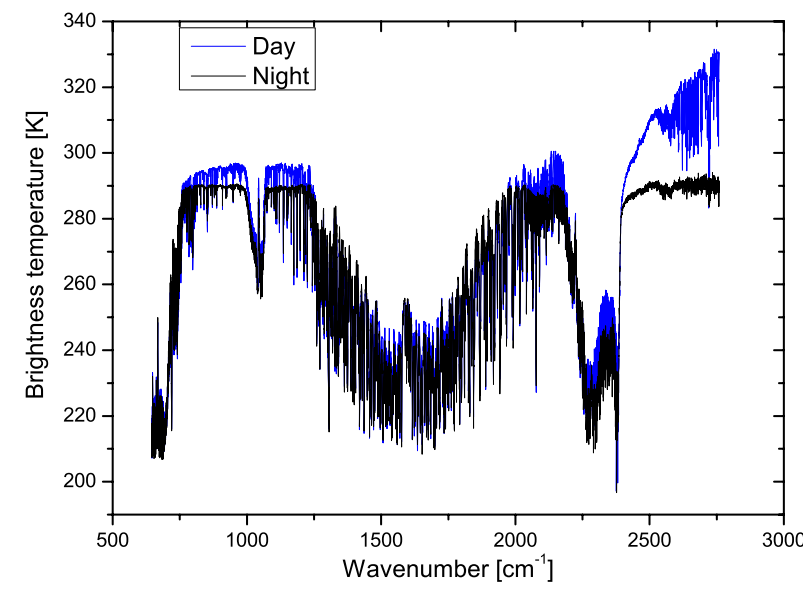

Fig. 2. Comparison of two IASI spectra in brightness temperature. One spectrum is recorded at night (black curve) and the other (in blue) during daytime with an important fraction of solar radiation reflected by the Earth's surface. The latter increases the source term mainly above $2200 \mathrm{~cm}^{-1}$.

vector $\boldsymbol{y}$ and an a priori state $\boldsymbol{x}_{a}$ which represents the best knowledge of the state $\boldsymbol{x}$ (from atmospheric model or prior measurements). These two quantities are weighted by covariance matrices, respectively $\mathbf{S}_{\rho}$ and $\mathbf{S}_{a}$, which define their spectral and/or spatio-temporal variations.

If we assume that the forward model is linear, Eq. 4 becomes $\boldsymbol{y}=\mathbf{K} \boldsymbol{x}+\boldsymbol{\rho}$ and the solution $\hat{\boldsymbol{x}}$ of the OEM can be written as

$\hat{\boldsymbol{x}}=\mathbf{A} \boldsymbol{x}+(\mathbf{I}-\mathbf{A}) \boldsymbol{x}_{a}+\mathbf{G} \boldsymbol{\rho}$

where $\mathbf{A}=\partial \hat{\boldsymbol{x}} / \partial \boldsymbol{x}$ is the averaging kernel matrix and $\mathbf{G}=\partial \hat{\boldsymbol{x}} / \partial \boldsymbol{y}$ is the gain matrix. The averaging kernel matrix represents the sensitivity of the retrieved profile to the true state and allows to characterize the retrieval in terms of vertical sensitivity. Indeed, the retrieved value at some altitude level is given by the true profile weighted by the corresponding row of $\mathbf{A}$ and corrected with the other terms accounting for the a priori information and the measurement noise. In addition, the trace of the $\mathbf{A}$ matrix, called degrees of freedom for signal (DFS), gives an estimation of the number of vertical independent pieces of information obtained. It follows also that the position of the largest diagonal element of $\mathbf{A}$ corresponds to the altitude where the sensitivity is the highest.

In our case, the problem is moderately non-linear and may be solved through an iterative process (fit) of the form

$$
\begin{aligned}
\hat{\boldsymbol{x}}_{i+1}=\boldsymbol{x}_{a}+\left(\mathbf{S}_{\mathbf{a}}^{-\mathbf{1}}\right. & \left.+\mathbf{K}_{i}^{T} \mathbf{S}_{\boldsymbol{\rho}}^{-\mathbf{1}} \mathbf{K}_{i}\right)^{-1} \mathbf{K}_{i}^{T} \mathbf{S}_{\boldsymbol{\rho}}^{-\mathbf{1}} \\
& \times\left[\boldsymbol{y}-\boldsymbol{F}\left(\hat{\boldsymbol{x}}_{i}\right)+\mathbf{K}_{i}\left(\hat{\boldsymbol{x}}_{i}-\boldsymbol{x}_{a}\right)\right]
\end{aligned}
$$

where $\mathbf{K}=\partial \boldsymbol{y} / \partial \boldsymbol{x}$ is the Jacobian matrix and $\mathbf{K}_{i}=\mathbf{K}\left(\boldsymbol{x}_{i}\right)$. The solution is obtained when convergence is achieved i.e. when

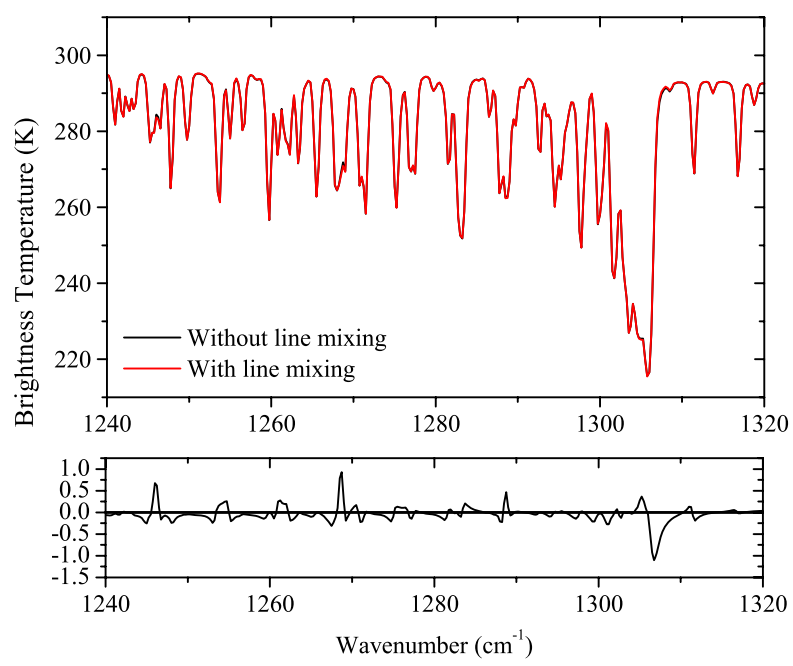

Fig. 3. Simulation of a IASI spectrum with (red curve) and without (black curve) line mixing of methane. The bottom panel gives the difference between the two simulated spectra.

$\left|\boldsymbol{F}\left(\boldsymbol{x}_{i+1}\right)-\boldsymbol{F}\left(\boldsymbol{x}_{i}\right)\right| \leq 0.7 \times \sigma_{\rho}$, where $\sigma_{\rho}$ are the diagonal elements of the matrix $\mathbf{S}_{\rho}=\sigma_{\rho}^{2} \mathbf{I}$.

\subsection{Spectral range selection}

The accuracy achieved in the retrieval of trace species from remote sensing measurements relies on the performance of the sounders, on the availability of auxiliary data such as $\mathrm{H}_{2} \mathrm{O}$ and temperature profiles and on the quality of spectroscopic data introduced as input of the radiative transfer algorithms. Standard line-by-line spectroscopic data include line positions and intensities, broadening and shifting coefficients as well as their temperature dependence. For this work, they are taken from the HITRAN 2004 database (Rothman et al., 2005). These parameters must be complemented by information on physical effects affecting the shape of atmospheric lines beyond the usual Voigt profile approximation. These include line narrowing and line interference effects, which are to be considered when processing high spectral resolution atmospheric spectra. In addition, the instrumental lineshape of IASI is also included in the computations.

We explore here the impact of line mixing, known to affect methane spectroscopy, on the retrieval of concentration profiles of this molecule from IASI spectra in the $v_{4}$ spectral band around $1300 \mathrm{~cm}^{-1}$. Similar studies evaluating the impact on the methane retrievals of fine spectroscopy in the $v_{3}$ band (Mondelain et al., 2007) have been performed using balloon and ground based high resolution spectra in solar absorption (Tran et al., 2006). Concerning the $v_{4}$ band, the maximum information content is centered on the methane $Q$ branch located around $1306 \mathrm{~cm}^{-1}$. As is obvious from Fig. 1, this region also contains strong water and nitrous oxide lines, which complicates the retrievals. 

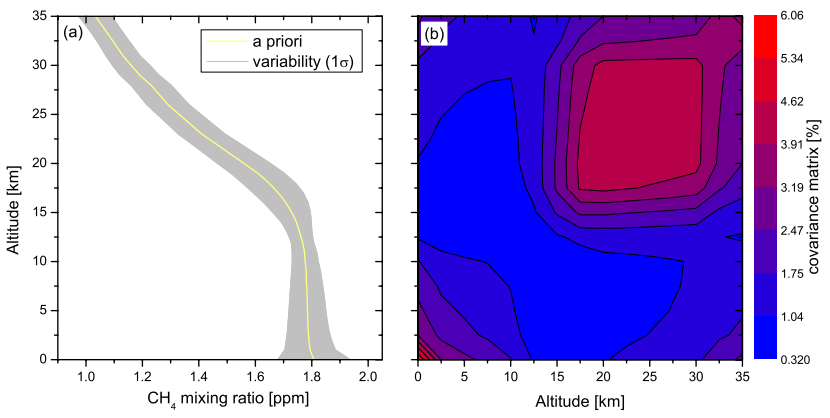

Fig. 4. A priori information derived from an ensemble of LMDZ model profiles for four days, each characterizing one season. The standard deviation values were multiplied by two to increase the variability. (a) The a priori profile (yellow curve) and its associated variability (grey area) represented by the standard deviation $(1 \sigma)$ which is derived from the covariance matrix. (b) Surface plot of the Sa matrix, in \%, illustrating both the variability (diagonal elements) and the degree of correlation between the different levels (off diagonal elements).

A first retrieval test has been done using the entire $v_{4}$ spectral range. In this case, the residual was found to be significantly higher than the instrumental noise. In order to improve the fits, the line mixing parameters from Tran et al. (2006) have been used to generate absorption cross sections of methane. Figure 3 presents resulting forward simulations of IASI spectra, with and without taking line mixing into account. As can be seen in the residual (expressed in brightness temperature) the differences can reach $1 \mathrm{~K}$ around the methane $Q$ branch, which is larger by more than one order of magnitude than the expected instrumental noise of IASI in this spectral region. The impact on the retrieved column was, however, found to be minor. In order to simplify the radiative transfer, we have chosen not to include line mixing in the model, but we have excluded the more strongly affected $Q$ branch from the retrieval window to improve on the residuals. Wavenumbers above $1310 \mathrm{~cm}^{-1}$ are not taken into account in order to minimize possible effects due to the water vapor continuum. The resulting spectral window used for methane concentration retrieval in the $v_{4}$ band thus extends from 1240 to $1290 \mathrm{~cm}^{-1}$.

\subsection{Retrieval settings}

The a priori profile and variability chosen for the retrieval of methane are derived from LMDZ global model distributions (Hauglustaine et al., 2004). Four days corresponding to the different seasons of the year 2004 (January, April, July and October) were used to create a global mean a priori profile from 0 to $60 \mathrm{~km}$ and an associated a priori covariance matrix. Owing to the fact that the LMDZ model is mainly dedicated to the troposphere, the a priori has been connected above $20 \mathrm{~km}$ to the one used in previous studies (Turquety et al., 2004). As the model usually tends to smooth the spatial variability, we have also chosen to multiply by 2 the $\mathbf{S}_{\mathbf{a}}$ covariance matrix built from LMDZ. Figure 4 presents on one hand the a priori profile and its associated variability limited on both ends by the standard deviation value, and on the other hand the surface plot of the $\mathbf{S}_{\mathbf{a}}$ matrix which also highlights the a priori vertical correlation between the layers. It can be seen that the model $\mathbf{S}_{\mathbf{a}}$ matrix shows a large correlation length (about $8 \mathrm{~km}$ ), with off-diagonal elements that still make up half of the ground variability in the middle troposphere (the off-diagonal elements correlating the free troposphere to the surface range from 1 to $3 \%$ while surface variability is about 5\%). Preliminary tests suggest that using a different covariance matrix with uncorrelated layers does not significantly increase vertical sensitivity. Although the same prior information is used for different locations in order to avoid a dependence upon the a priori on the latitudinal scale, it is noteworthy that North-South gradients are present in the model $(6.8 \%$ in the troposphere from 0 to $10 \mathrm{~km}$ and $2.9 \%$ in the lower stratosphere from 15.5 to $20 \mathrm{~km}$ between the $\mathrm{NH}$ from $30^{\circ}$ to $90^{\circ}$ and the $\mathrm{SH}$ from $-30^{\circ}$ to $-90^{\circ}$ ). The diagonal elements of the measurement covariance matrix $\mathbf{S}_{\rho}$ are given by $\sigma_{\rho}=2.00 \times 10^{-6} \mathrm{~W} /\left(\mathrm{m}^{2} \mathrm{sr} \mathrm{m}^{-1}\right)$, which is in good agreement with the IASI instrumental noise in the $v_{4}$ spectral region of interest.

\section{Results}

\subsection{Vertical sensitivity of the measurement}

IASI provides information on some trace gases (including $\mathrm{CH}_{4}$ ) with limited vertical resolution (Clerbaux et al., 2009). The averaging kernels corresponding to three typical cases of methane retrievals in the $v_{4}$ spectral region (tropical, midlatitude and polar observations) are represented in Fig. 5. Note that the averaging kernels are plotted against the middle of the retrieval layers in such a way that the first point is located at $1.5 \mathrm{~km}(0-3 \mathrm{~km}$ layer). The retrieval was set-up for partial columns of $3 \mathrm{~km}$ thickness, extending from the ground up to $21 \mathrm{~km}$. These partial columns were chosen to fully characterize the measurement even though the different levels are correlated through the $\mathbf{S}_{\mathbf{a}}$ matrix. It follows from the shape of the averaging kernels that the IASI measurements have a maximum sensitivity to methane in the middle troposphere, between approximately 4 and $10 \mathrm{~km}$ and between 7 and $14 \mathrm{~km}$ for tropical regions. The resulting DFS for the 3 scenes shown in Fig. 5 are equal to $1.16,1.04$ and 0.92 , respectively (this is smaller than for CO where the DFS frequently reaches values above 1.5, see Turquety et al., 2009). Even in the most favorable situation (hot tropical scene) the decorrelation of two tropospheric columns is not possible. It follows that we consider only the total columns for the derivation of global distributions. The column is mostly driven by the free troposphere where IASI sensitivity is highest. 


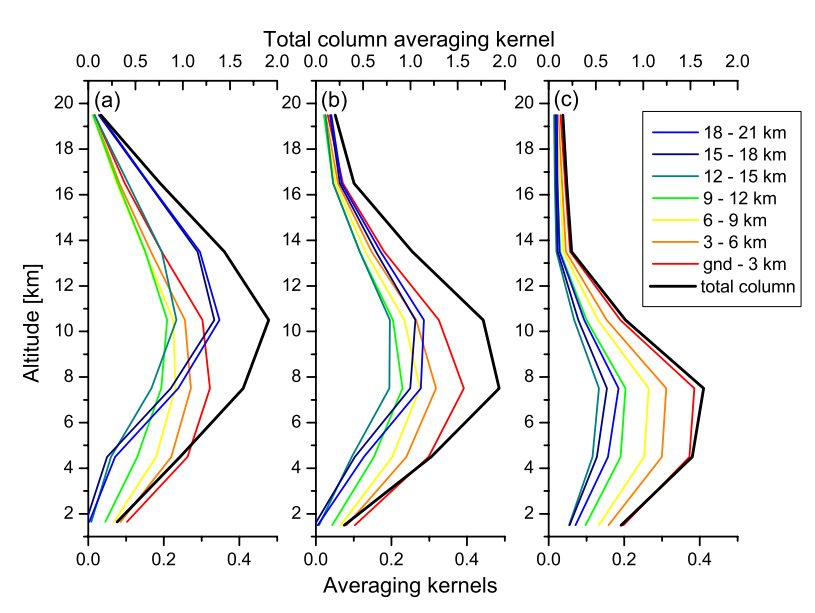

Fig. 5. Averaging kernels presented in mixing ratios unit for representative cases of (a) tropical, (b) midlatitude and (c) polar regions. The black curves represent the total column averaging kernels, with absolute values given by the top scale. The averaging kernels rows are plotted with respect to the middle of the retrieval layers.

A typical error budget for methane retrievals in the $v_{4}$ band is provided in Fig. 6. The total retrieval error varies between 1 and $2.5 \%$ in the troposphere below $12 \mathrm{~km}$, closely following the shape of the a priori variability. It provides an improvement on the a priori uncertainty of about a factor 2 from the Earth surface to about $12 \mathrm{~km}$ height. In the upper troposphere, the sensitivity slightly decreases leading to a gain of 1.5 with respect to the variability. The total error is mostly driven by the smoothing error. Other significant sources of error are introduced from the instrumental noise (referred here as the measurement error) and to a lesser extent from the uncertainties in the fitted humidity profile. The retrieval error of the methane total column (from 0 to $21 \mathrm{~km}$ ) resulting from the OEM can be as small as $1 \%$. However, the value of the column error is intimately related to the a priori variability and correlations between the levels of the profile. Considering that much larger variability can occur in the boundary layer nearby source regions, where IASI is less sensitive, this value is obviously a lower bound to the error: in fact it is only valid for cases which are included in the ensemble of profiles used to built the a priori matrix. Other cases, and in particular those showing enhancement in the boundary layer will not be reproducible with this accuracy.

In order to better show this, we have tested the IASI capability to detect a $\mathrm{CH}_{4}$ source region with forward model simulations. Figure 7 provides the transmittance differences in the spectral range selected between the methane a priori profile and a $200 \mathrm{ppb}$ methane increase in the boundary layer. Simulations with different values of thermal contrast (i.e. the difference between the ground temperature and the temperature of the first atmospheric layer) from +0.5 to $+20 \mathrm{~K}$ have been performed. The comparison between these simulations and the IASI noise (green curve) shows that IASI should de-

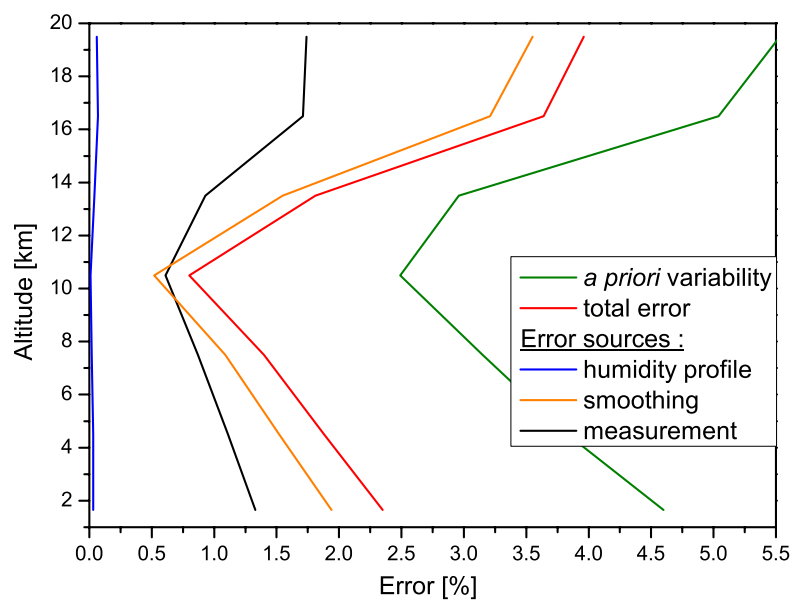

Fig. 6. Error profiles for methane retrievals in the $v_{4}$ band. The contributions from the smoothing, the measurement error and the error from the water vapor profile are shown and compared to the a priori variability.

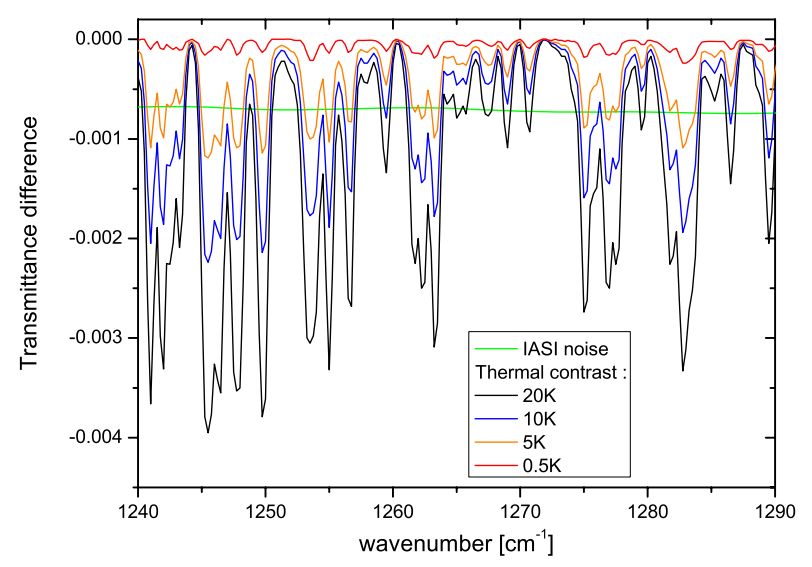

Fig. 7. Simulation of the signal difference (in transmittance) with a $200 \mathrm{ppb}$ methane enhancement near the Earth's surface. The different curves represent different values of thermal contrast up to $+20 \mathrm{~K}$. The IASI instrumental noise is as well illustrated in green.

tect the $10 \%$ increase of $\mathrm{CH}_{4}$ for cases when the thermal contrast exceeds $5 \mathrm{~K}$ although the constrain of the $\mathbf{S}_{\mathbf{a}}$ matrix will induce some underestimation. A full error characterization will have to be evaluated at a later stage by a detailed validation exercise.

\subsection{Global distribution}

In this section, we show the preliminary global distribution of methane total columns assessed from the IASI sounder; as explained before the columns are representative of the middle troposphere (see the averaging kernels on Fig. 5). Because inversion is computationally very demanding, especially given the large number of IASI spectra, we have 


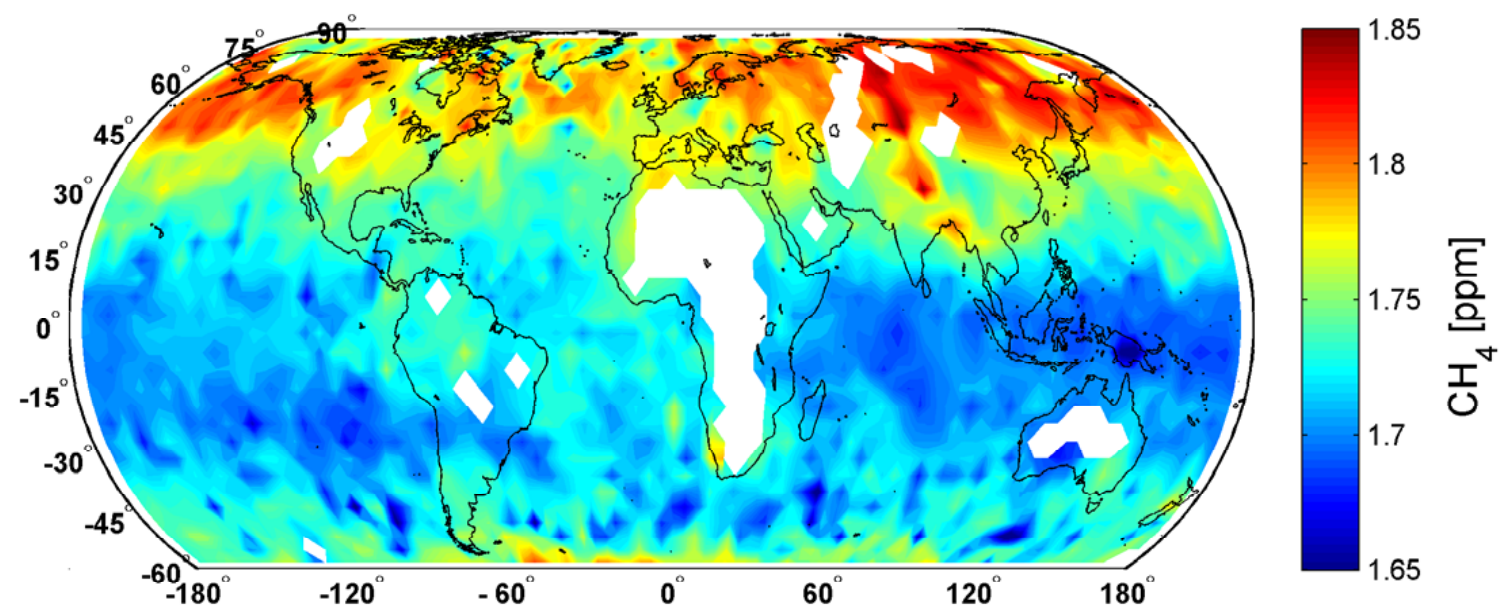

Fig. 8. Methane global distribution expressed in averaged vmr $(\mathrm{ppm})$ and interpolated on a $4^{\circ} \times 4^{\circ}$ grid containing nadir measurements from 4 to 10 October 2008 . Data below $60^{\circ} \mathrm{S}$ has been filtered out because of low signal around the Antarctic.

chosen to limit the retrieval to near-nadir spectra (satellite zenithal angles $\leq 3^{\circ}$ ) during 7 successive days, from $4-10$ October 2008. The a priori profiles used for temperature and humidity are those disseminated operationally by EUMETCast along with cloud information (pressure, temperature and coverage). Only cloud-free observations as characterized with the level 2 data (cloud coverage $\leq 15 \%$ ) have been processed. In addition, some filters were applied after the methane retrievals: total columns corresponding to a RMS of the difference between the observed and calculated spectra higher than $4 \times 10^{-6} \mathrm{~W} /\left(\mathrm{m}^{2} \mathrm{sr} \mathrm{m}^{-1}\right)$ (i.e. about twice the instrumental noise in this spectral region), with an emissivity (calculated as the average from 12 channels from the Moderate Resolution Imaging Spectroradiometer/Terra climatology) lower than 0.96 and with a relative error (accounting only for the retrieval error provided by the OEM) exceeding $1.5 \%$ on the total column were filtered out.

In the retrieval we find that the retrieved columns of $\mathrm{CH}_{4}$ are too large by about $8 \%$ as compared to the range of values reported in the literature, either from the satellite or from the ground. This overestimation is likely due to retrieval problems in this difficult spectral region where many parameters are likely to affect the baseline radiance (emissivity, ground temperature, water continuum). In order to minimize these effects, we have chosen here to normalize the $\mathrm{CH}_{4}$ retrieved columns by those of $\mathrm{N}_{2} \mathrm{O}$, simultaneously retrieved in that same spectral window. This also allows to reduce the impact of the ground altitude on the total column, as also done in SCIAMACHY retrievals where the methane columns were divided by the $\mathrm{CO}_{2}$ column (Frankenberg et al., 2006). The formula we used is

$v m r_{\mathrm{CH}_{4}}^{r e t .}=\frac{T C_{\mathrm{CH}_{4}}^{\text {ret. }}}{T C_{\mathrm{N}_{2} \mathrm{O}}^{\text {ret. }}} v m r_{\mathrm{N}_{2} \mathrm{O}}^{\mathrm{ref}}$, where $v m r_{\mathrm{CH}_{4}}^{\text {ret. }}$ is the methane column averaged vmr, $T C^{\text {ret. }}$ is the retrieved total column of methane or nitrous oxide and $v m r_{\mathrm{N}_{2} \mathrm{O}}^{\text {ref }}=319 \mathrm{ppb}$ is the reference mixing ratio of $\mathrm{N}_{2} \mathrm{O}$ as given in (Forster et al., 2007).

The global distribution (see Fig. 8) is illustrated on a $4 \times 4^{\circ}$ grid. High values found over the Antarctic are rejected by posterior filters but some unrealistically large values above these cold regions remain (not shown on the figure). Excluding these extremes values, the methane normalized mixing ratios range from 1.65 in tropical regions up to $1.88 \mathrm{ppm}$ at high northern latitudes with a distinct North-South gradient. The cut-off from low to high concentrations is located around $20^{\circ} \mathrm{N}$ with a further steady increase towards the polar region. The elevated methane concentrations at mid and high latitudes could be related to the locations of large methane emission sources (such as rice agriculture, livestock and wetlands).

Comparing the global distributions of total columns with other satellites is a difficult task, mainly because of the vertical sensitivities inherent to each observing modes. For example, regarding the AIRS distribution (Xiong et al., 2008), the observations are expressed in mixing ratios for two vertical layers (150-250 hPa and 450-550 hPa) averaged for the month of August 2004. Given the IASI vertical sensitivity, the comparison with the layer between 450 and $550 \mathrm{hPa}$ is more relevant. The range of IASI methane column averaged vmr is in good agreement with the AIRS mixing ratios corresponding to partial columns (extending from 1.65 to $1.9 \mathrm{ppm}$ ) and the North-South gradient is similar in strength and location. The tropical IASI distributions shown in (Crevoisier et al., 2009) give as well similar concentrations. However, our methane averaged column present lower values in the tropics (about $20 \mathrm{ppb}$ ) than both products, indicating the possible contamination by water vapor in humid regions. Concerning SCIAMACHY, the methane product is an averaged 


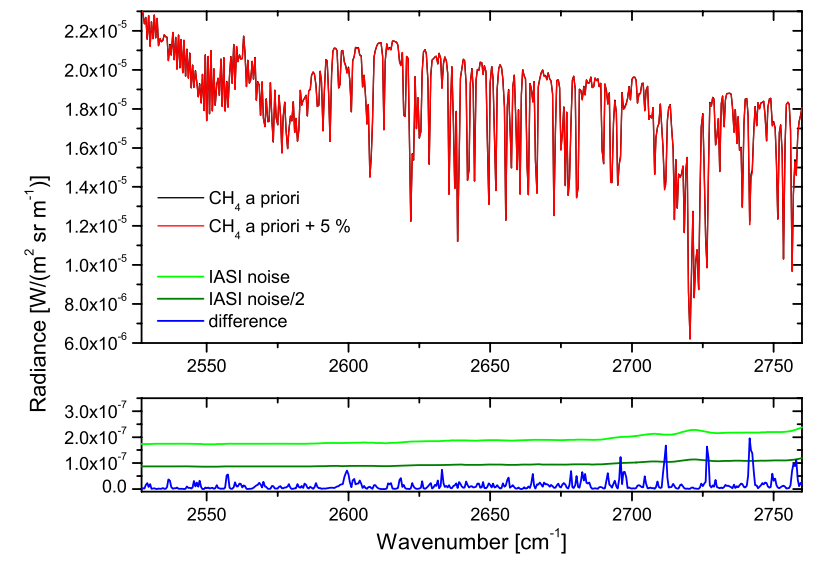

Fig. 9. Simulations of two spectra with a difference of $5 \%$ in the methane total column. In addition, the difference in radiance is compared to the IASI spectral noise.

vmr more representative to the lower troposphere than the IASI one (Frankenberg et al., 2008b). The concentration range is therefore slightly different (1.63 to $1.81 \mathrm{ppm}$ for SCIAMACHY) and only enables the qualitative comparison between the two global distributions. Doing this, we observe that the latitudinal gradient from the yearly averaged distribution of SCIAMACHY is sharper and located farther south. It also points out strong methane emissions in various parts of the world. It is worth noting that important sources over Southeast Asia in summertime that were reported from AIRS (Xiong et al., 2008), and also identified in independent IASI retrievals (Crevoisier et al., 2009), are not seen here. This might be due to the fact that different time periods are analyzed, and both emission sources and sensitivity to the surface vary as a function of the season..

\subsection{Additional information from the $v_{3}$ band}

One of the advantages of the extended spectral range of IASI is the presence of some $\mathrm{P}$ lines of the methane $\nu_{3}$ band. Owing to the influence of solar radiation reflected on the Earth's surface from $2000 \mathrm{~cm}^{-1}$ onwards (see Fig. 2), this spectral region is expected to provide additional information on $\mathrm{CH}_{4}$ in the boundary layer. The signal-to-noise ratio in this part of the IASI spectrum is, however, much smaller than in the $v_{4}$ region and depends significantly on the intensity of the solar reflection (i.e. on the reflectance parameter, $\eta$ in Eq. 3). Methane retrievals from this part of the IASI spectra are performed considering a wide range (from 2527 to $2760 \mathrm{~cm}^{-1}$, shown in gray in Fig. 1) which allows the simultaneous retrieval of the reflectance. The contribution of nitrous oxide and HDO are also taken into account in the retrieval process. Figure 9 shows that a value of reflected solar radiation $\eta=5 \times 10^{-6}$ is not sufficient to increase the signal-tonoise such as to observe a variation of $5 \%$ in the total column of methane. In order to improve on the signal-to-noise and
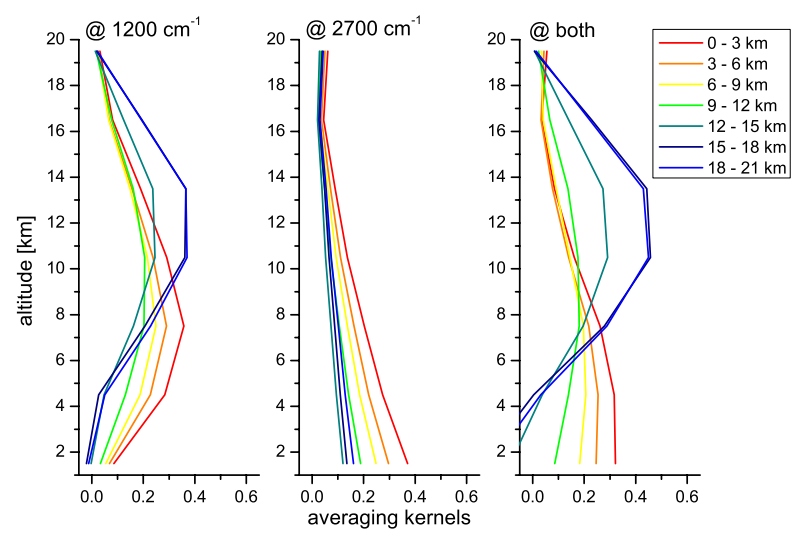

Fig. 10. Averaging kernels (in units of mixing ratios) corresponding, respectively to the retrieval of methane in the $1240-1290 \mathrm{~cm}^{-1}$ spectral range ( $v_{4}$ band, left panel), in the $2527-2760 \mathrm{~cm}^{-1}$ spectral region ( $\nu_{3}$ band, middle panel) and in both (right panel).

make adequate use of the $v_{3}$ absorption band, 4 contiguous IASI measurements $(50 \times 50 \mathrm{~km})$ have been averaged.

As an example, the average is performed here on 4 spectra measured on 20 January 2009 above the Indian ocean (around $-6.81^{\circ}$ latitude and $78.02^{\circ}$ longitude). This sunglint contaminated spectrum is characterized by a fitted reflectance of $6.54 \times 10^{-6}$.

Figure 10 illustrates the vertical sensitivity achievable using the $v_{3}$ band in comparison to using the $v_{4}$ band. The combination of both bands in a joint retrieval is also shown. The retrieval of methane from the $v_{4}$ band provides, as shown earlier, higher sensitivity in the mid to upper troposphere and low sensitivity below $2 \mathrm{~km}$. In contrast, the $v_{3}$ band contains the maximum information from the ground to $4 \mathrm{~km}$, complementing the information from the $v_{4}$ band. The simultaneous fit of the two spectral regions leads accordingly to an improvement of sensitivity throughout the troposphere as compared to the bands used individually. In particular, it allows a better decorrelation of two partial columns (from the ground to $8 \mathrm{~km}$ and from 8 to $15 \mathrm{~km}$ ). In terms of vertical independent pieces of information, the DFS values range from 0.91 using the $\nu_{3}$ band alone, 1.22 using $\nu_{4}$ and up to 1.46 using both bands simultaneously. The simultaneous retrieval allows thus for a gain of 0.24 DFS, which corresponds principally to the increase of sensitivity near the ground.

The $\mathrm{CH}_{4}$ profiles retrieved, using those different choices of spectral windows and corrected in the same way has the total columns with $\mathrm{N}_{2} \mathrm{O}$, are shown in Fig. 11 for the selected scene together with the associated errors. The blue and orange curves correspond to the retrieval of methane from the $v_{4}$ and $v_{3}$ bands, respectively. Care should be taken in interpreting these values as high water vapor concentrations are present in this region, which could bias the methane retrieval (as mentioned in the global distribution description), Fig. 11 is in itself illustrative of the relative sensitivities of the $v_{3}$ and 


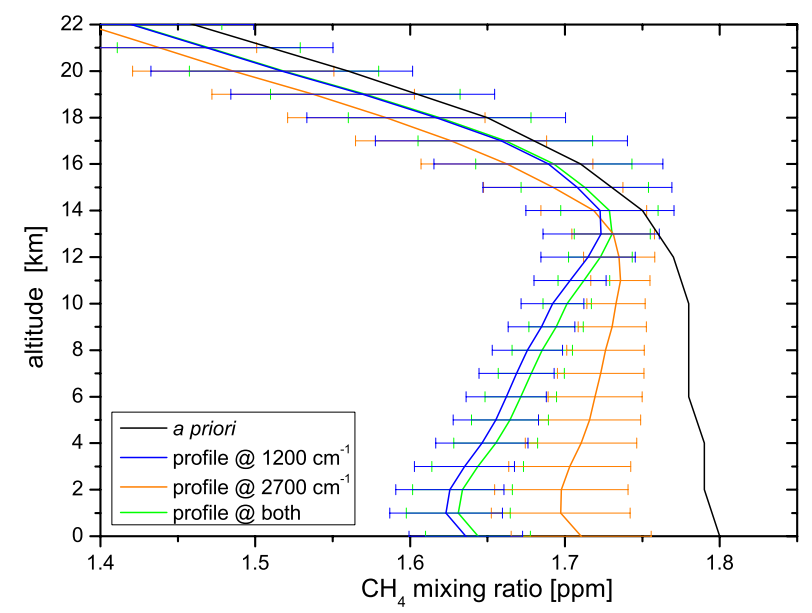

Fig. 11. Methane profiles retrieved from different spectral regions. Using the same a priori profile (black curve), the blue profile is derived from the $v_{4}$ band, the orange one from the $v_{3}$ band and the green profile results from the simultaneous inversions in both bands.

$v_{4}$ bands to the vertical structure. The retrieved profile from the spectral range around $2700 \mathrm{~cm}^{-1}$ (orange curve) departs mostly from the a priori in the lower troposphere, illustrating the sensitivity present in these layers. In addition, we observe that the profile retrieved using both bands (green curve) is similar to the profile derived from the $v_{3}$ band alone, except from a shift towards the retrieved profile using the $v_{4}$ band alone, confirming the complementarity of the two windows in terms of vertical sensitivity.

In order to fully determine what the methane retrievals in the $v_{3}$ band have to offer, more tests must be conducted. We expect to observe a larger signal for off-nadir recorded spectra as the angle between the sun and the satellite plays a significant role in the reflectance value. However, due to the decrease of the surface temperature, lower sensitivity is expected at high latitudes.

\section{Conclusions and perspectives}

Thanks to the wide spectral range and low instrumental noise of the IASI/MetOp thermal infrared sounder, methane may be retrieved in two different spectral regions which lead to different vertical sensitivities. We have firstly derived global distributions of methane averaged column vmr (normalized with the nitrous oxide column) using the $v_{4}$ absorption band. The retrieval spectral range, extending from 1240 to $1290 \mathrm{~cm}^{-1}$, has been chosen in order to avoid the spectroscopic line mixing issues that can affect the methane retrievals, especially in the $Q$ branch. The resulting global distribution of one week in October 2008 shows a clear NorthSouth gradient with a sharp increase (up to $7.9 \%$ higher in the Northern hemisphere in comparison with tropical methane) from $20^{\circ} \mathrm{N}$ to higher latitudes. We have shown that these distributions retrieved from the $v_{4}$ band are mostly representative of methane concentrations in the middle troposphere, from 4 to $10 \mathrm{~km}$. The retrieval error (which only accounts for the smoothing error, measurement error and the error from the humidity profile) estimated in this study is to be considered as a lower bound to the error in case of background methane profiles. As discussed in Sect. 3.1, a more quantitative evaluation of the accuracy associated with the IASI $\mathrm{CH}_{4}$ product will only be possible by performing a large validation exercise, which is outside the scope of this paper.

In this work, we have also demonstrated the possibility for IASI to add information on methane in the boundary layer using information from the $\nu_{3}$ band when the reflected solar radiation is high enough. Further studies will be conducted on a larger scale to work out the full extent of what this spectral region has to offer.

Further improvements in the IASI processing chain will be implemented in the near future. In particular, a faster retrieval method (FORLI which stands for Fast Operational Retrievals on Layers for IASI) based on lookup tables is currently under construction. This software will be able to provide nearly operationally the distributions of methane. This method has been successfully applied to nitric acid (Wespes et al., 2009) and carbon monoxide (George et al., 2009).

The retrieval of methane global distributions daily will obviously be a major advance which will allow to take advantage of the IASI potential in terms of spatio-temporal coverage and will also allow systematic validations with other available spaceborne (AIRS, SCIAMACHY) and groundbased measured data.

Acknowledgements. IASI has been developed and built under the responsibility of the Centre National d'Etudes Spatiales (CNES, France). It is flown onboard the MetOp satellites as part of the EUMETSAT Polar System. The IASI L1 data are received through the EUMETCast near real time data distribution service. The research in Belgium was funded by the "Communauté Française de Belgique - Actions de Recherche Concertées", the Fonds National de la Recherche Scientifique (FRS-FNRS F.4511.08), the Belgian State Federal Office for Scientific, Technical and Cultural Affairs and the European Space Agency (ESA-Prodex C90-327). We acknowledge as well the referees which have greatly helped to the improvement of the paper.

Edited by: A. Richter

\section{References}

Boynard, A., Clerbaux, C., Coheur, P.-F., Hurtmans, D., Turquety, S., George, M., Hadji-Lazaro, J., Keim, C., and MayerArnek, J.: Measurements of total and tropospheric ozone from IASI: comparison with correlative satellite, ground-based and ozone sonde observations, Atmos. Chem. Phys., 9, 6255-6271, 2009, http://www.atmos-chem-phys.net/9/6255/2009/.

Clarisse, L., Coheur, P.-F., Prata, A. J., Hurtmans, D., Razavi, A., Hadji-Lazaro, J., Clerbaux, C., and Phulpin, T.: Tracking and 
quantifying volcanic $\mathrm{SO}_{2}$ with IASI, the September 2007 eruption at Jebel-at-Tair, Atmos. Chem. Phys., 8, 7723-7734, 2008, http://www.atmos-chem-phys.net/8/7723/2008/.

Clarisse, L., Clerbaux, C., Dentener, F., Hurtmans, D., and Coheur, P.-F.: Infrared space observations unveil first global distribution of ammonia, Nature Geosci., advance online publication, doi:10.1038/ngeo551, 2009.

Clerbaux, C., Hadji-Lazaro, J., Turquety, S., Mégie, G., and Coheur, P.-F.: Trace gas measurements from infrared satellite for chemistry and climate applications, Atmos. Chem. Phys., 3, 1495-1508, 2003,

http://www.atmos-chem-phys.net/3/1495/2003/.

Clerbaux, C., Hadji-Lazaro, J., Turquety, S., George, M., Coheur, P.-F., Hurtmans, D., Wespes, C., Herbin, H., Blunmstein, D., Tournier, B., and Phulpin, T.: The IASI/MetOp mission: first observations and highlight of its potential contribution to the GMES Earth observation component, Space Res. Today, 168, 19-24, 2007.

Clerbaux, C., Boynard, A., Clarisse, L., George, M., HadjiLazaro, J., Hurtmans, D., Herbin, H., Pommier, M., Razavi, A., Turquety, S., Wespes, C., and Coheur, P.-F.: Monitoring of atmospheric composition using the thermal infrared IASI/METOP sounder, Atmos. Chem. Phys., 9, 6041-6054, 2009, http://www.atmos-chem-phys.net/9/6041/2009/.

Coheur, P.-F., Barret, B., Turquety, S., Hurtmans, D., HadjiLazaro, J., and Clerbaux, C.: Retrieval and characterization of ozone vertical profiles from a thermal infrared nadir sounder, J. Geophys. Res., 5, 4599-4639, 2005.

Coheur, P.-F., Clarisse, L., Turquety, S., Hurtmans, D., and Clerbaux, C.: IASI measurements of reactive trace species in biomass burning plumes, Atmos. Chem. Phys., 9, 5655-5667, 2009, http://www.atmos-chem-phys.net/9/5655/2009/.

Crevoisier, C., Nobileau, D., Fiore, A.M., Armante, R., Chédin, A., and Scott, N.A.: Tropospheric methane in the tropics - first year from IASI hyperspectral infrared observations, Atmos. Chem. Phys., 9, 6337-6350, 2009, http://www.atmos-chem-phys.net/9/6337/2009/.

De Mazière, M., Vigouroux, C., Bernath, P. F., Baron, P., Blumenstock, T., Boone, C., Brogniez, C., Catoire, V., Coffey, M., Duchatelet, P., Griffith, D., Hannigan, J., Kasai, Y., Kramer, I., Jones, N., Mahieu, E., Manney, G. L., Piccolo, C., Randall, C., Robert, C., Senten, C., Strong, K., Taylor, J., Tétard, C., Walker, K. A., and Wood, S.: Validation of ACE-FTS v2.2 methane profiles from the upper troposphere to the lower mesosphere, Atmos. Chem. Phys., 8, 2421-2435, 2008, http://www.atmos-chem-phys.net/8/2421/2008/.

Dentener, F., Derwent, R., Dlugokencky, E., Holland, E., Isaksen, I., Katima, J., Kirchhoff, V., Matson, P., Midgley, P., and M., W.: Climate Change 2001: The Scientific Basis. Contribution of Working Group I to the Third Assessment Report of the Intergovernmental Panel on Climate Change, chap. Atmospheric Chemistry and Greenhouse Gases, Cambridge University Press, Cambridge, and New York, 239-287, 2001.

Dlugokencky, E. J., Houweling, S., Bruhwiler, L., Masarie, K. A., Lang, P. M., Miller, J. B., and Tans, P. P.: Atmospheric methane levels off: Temporary pause or a new steady-state?, Geophys. Res. Lett., 30, 1992, doi:10.1029/2003GL018126, 2003.

Dueck, T. A., de Visser, R., Poorter, H., Persijn, S., Gorissen, A., de Visser, W., Schapendonk, A., Verhagen, J., Snel, J., Har- ren, F. J. M., Ngai, A. K. Y., Verstappen, F., Bouwmeester, H., Voesenek, L. A. C. J., and van der Werf, A.: No evidence for substantial aerobic methane emission by terrestrial plants: a $13 \mathrm{C}-$ labelling approach, New Phytol., 175, 29-35, doi:10.1111/j. 1469-8137.2007.02103.x, 2007.

Forster, P., Ramaswamy, V., Artaxo, P., Berntsen, T., Betts, R., Fahey, D. W., Haywood, J., Lean, J., Lowe, D. C., Myhre, G., Nganga, J., Prinn, R., Raga, G., Schulz, M., and Van Dorland, R.: Climate Change 2007: The Physical Science Basis. Contribution of working group 1 to the fourth assessment report of the Intergovernmental Panel on Climate Change, chap. Changes in Atmospheric Constituents and in Radiative Forcing, Cambridge University Press, Cambridge and New York, 129-234, 2007.

Denman, K. L., Brasseur, G., Chidthaisong, A., Ciais, P., Cox, P. M., Dickinson, R. E., Hauglustaine, D., Heinze, C., Holland, E., Jacob, D., Lohmann, U., Ramachandran, S., da Silva Dias, P. L., Wofsy, S. C., and Zhang, X.: Climate Change 2007: The Physical Science Basis. Contribution of working group 1 to the fourth assessment report of the Intergovernmental Panel on Climate Change, chap. Changes in Atmospheric Constituents and in Radiative Forcing, Cambridge University Press, Cambridge and New York, 499-587, 2007.

Frankenberg, C., Meirink, J. F., Bergamaschi, P., Goede, A. P. H., Heimann, M., Körner, S., Platt, U., van Weele, M., and Wagner, T.: Satellite chartography of atmospheric methane from SCIAMACHY on board ENVISAT: Analysis of the years 2003 and 2004, J. Geophys. Res., 111, D07303, doi:10.1029/2005JD006235, 2006.

Frankenberg, C., Warneke, T., Butz, A., Aben, I., Hase, F., Spietz, P., and Brown, L. R.: Pressure broadening in the $2 v_{3}$ band of methane and its implication on atmospheric retrievals, Atmos. Chem. Phys., 8, 5061-5075, 2008a,

http://www.atmos-chem-phys.net/8/5061/2008/.

Frankenberg, C., Bergamaschi, P., Butz, A., Houweling, S., Meirink, J. F., Notholt, J., Petersen, A., Schrijver, H., Warneke, T., and Aben, I.: Tropical methane emissions: A revised view from SCIAMACHY onboard ENVISAT, Geophys Res. Lett., 35, L15811, doi:10.1029/2008GL034300, 2008 b.

George, M., Clerbaux, C., Coheur, P.-F., Hadji-Lazaro, J., Hurtmans, D., Pommier, M., Turquety, S., Edwards, D., Worden, H., Luo, M., Rinsland, C. P., and Barnet, C.: Carbon monoxide distributions from the IASI/METOP mission : evaluation with other spaceborne remote sensors, Atmos. Chem. Phys. Discuss., 9, 9793-9822, 2009,

http://www.atmos-chem-phys-discuss.net/9/9793/2009/.

Hauglustaine, D. A., Hourdin, F., Jourdain, L., Filiberti, M.-A., Walters, S., Lamarque, J.-F., and Holland, E. A.: Interactive chemistry in the Laboratoire de Météorologie Dynamique general circulation model: Description and background tropospheric chemistry evaluation, J. Geophys. Res., 109, D04314, doi:10.1029/2003JD003957, 2004.

Herbin, H., Hurtmans, D., Clerbaux, C., Clarisse, L., and Coheur, P.-F.: H216O and HDO measurements with IASI/MetOp, Atmos. Chem. Phys. Discuss., 9, 9267-9290 2009.

Keppler, F., Hamilton, J. T. G., Braß, M., and Röckmann, T.: Methane emissions from terrestrial plants under aerobic conditions, Nature, 439, 187-191, 2006.

Keppler, F., Hamilton, J. T. G., McRoberts, W., Vigano, I., Braß, M., and Röckmann, T.: Methoxyl groups of plant pectin as a precur- 
sor of atmospheric methane, New Phytol., 4, 808-814, 2008.

Kulawik, S. S., Bowman, K. W., Luo, M., Rodgers, C. D., and Jourdain, L.: Impact of nonlinearity on changing the a priori of trace gas profile estimates from the Tropospheric Emission Spectrometer (TES), Atmos. Chem. Phys., 8, 3081-3092, 2008, http://www.atmos-chem-phys.net/8/3081/2008/.

Mondelain, D., Payan, S., Deng, W., Camy-Peyret, C., Hurtmans, D., and Mantz, A. W.: Measurement of the temperature dependence of line mixing and pressure broadening parameters between 296 and $90 \mathrm{~K}$ in the 3 band of ${ }^{12} \mathrm{CH}_{4}$ and their influence on atmospheric methane retrievals, J. Molec. Spectrosc., 130137, 2007.

Park, M., Randel, W. J., Kinnison, D. E., Garcia, R. R., and Choi, W.: Seasonal variation of methane, water vapor, and nitrogen oxides near the tropopause: Satellite observations and model simulations, J. Geophys. Res., 109, D03302, doi:10.1029/2003JD003706, 2004.

Phulpin, T., Blumstein, D., Prel, F., Tournier, B., Prunet, P., and Schlüssel, P.: Applications of IASI on MetOp-A: first results and illustration of potential use for meteorology, climate monitoring and atmospheric chemistry, Proc. SPIE, p. 6684, 2007.

Raspollini, P., Belotti, C., Burgess, A., Carli, B., Carlotti, M., Ceccherini, S., Dinelli, B. M., Dudhia, A., Flaud, J.-M., Funke, B., Höpfner, M., López-Puertas, M., Payne, V., Piccolo, C., Remedios, J. J., Ridolfi, M., and Spang, R.: MIPAS level 2 operational analysis, Atmos. Chem. Phys., 6, 5605-5630, 2006, http://www.atmos-chem-phys.net/6/5605/2006/.

Rigby, M., Prinn, R., Fraser, P., Simmonds, P., Langenfelds, R., Huang, J., Cunnold, D., Steele, P., Krummel, P., Weiss, R., O’Doherty, S., Salameh, P., Wang, H., Harth, C., Mühle, J., and Porter, L.: Renewed growth of atmospheric methane, Geophys. Res. Lett., 35, L22805, doi:10.1029/2008GL036037, 2008.

Rodgers, C. D.: Inverse methods for atmospheric sounding: theory and practise, University of Oxford, World Sci., River Edge, NJ, USA, 2000.
Rothman, L. S., Jacquemart, D., Barbe, A., Benner, D. C., Birk, M., Brown, L. R., Carleer, M. R., Chackerian, C., Chance, K., Coudert, L. H., et al.: The HITRAN 2004 molecular spectroscopic database, J. Quant. Spectrosc. Rad. T., 96, 139-204, 2005.

Tran, H., Flaud, P.-M., Gabard, T., Hase, F., von Clarmann, T., Camy-Peyret, C., Payan, S., and Hartmann, J.-M.: Model, software, and database for line-mixing effects in the 3 and 4 bands of $\mathrm{CH}_{4}$ and tests using laboratory and planetary measurements. I. $\mathrm{N}_{2}$ (and air) broadenings and the earth atmosphere, J. Quant. Spectrosc. Radiat. T., 101, 284-305, 2006.

Turquety, S., Hadji-Lazaro, J., Clerbaux, C., Hauglustaine, D., Clough, S. A., Cassé, V., and Schlüssel, P.: Operational trace gas retrieval algorithm for the infrared atmospheric sounding interferometer, J. Geophys. Res., 109(D21), D21301, doi:10.1029/2004JD004821, 2004.

Turquety, S., Hurtmans, D., Hadji-Lazaro, J., Coheur, P.-F., Clerbaux, C., Josset, D., and Tsamalis, C.: Tracking the emission and transport of pollution from wildfires using the IASI CO retrievals: analysis of of the summer 2007 Greek fires, Atmos. Chem. Phys., 9, 4897-4913, 2009, http://www.atmos-chem-phys.net/9/4897/2009/.

Vigano, I., van Weelden, H., Holzinger, R., Keppler, F., McLeod, A., and Röckmann, T.: Effect of UV radiation and temperature on the emission of methane from plant biomass and structural components, Biogeosciences, 5, 937-947, 2008, http://www.biogeosciences.net/5/937/2008/.

Wespes, C., Hurtmans, D., Clerbaux, C., Santee, M. L., Martin, R. V., and Coheur, P.-F.: Global distributions of nitric acid from IASI/MetOP measurements, Atmos. Chem. Phys. Discuss., 9, 8035-8069, 2009, http://www.atmos-chem-phys-discuss.net/9/8035/2009/.

Xiong, X., Barnet, C., Maddy, E., Sweeney, C., Liu, X., Zhou, L., and Goldberg, M.: Characterization and validation of methane products from the Atmospheric Infrared Sounder (AIRS), J. Geophys. Res., 113, G00A01, doi:10.1029/2007JD000500, 2008. 